\title{
The business transformation enterprise architecture framework for innovation \\ The role of artificial intelligence in the global business education (RAIGBE)
}

\author{
Antoine Trad \\ IBISTM. France.
}

\begin{abstract}
Keywords
Global Business Education, Artificial Intelligence, Hyper-heuristics, Business Transformation Manager's Profile, Transformation Project, Strategic and Critical Business Systems, Enterprise Architecture and Critical Success Factor.
\end{abstract}

\begin{abstract}
This article analyses the role of Global Business Education (GBE) and proposes the Applied Holistic Mathematical Model for GBE (AHMM4GBE). The AHMM4GBE is based on a lifetime long research on business transformations, Artificial Intelligence (AI), applied mathematics, software modelling, business engineering, educational systems, financial analysis, security and enterprise architecture. The used research methodology is based on the author's authentic mixed research method that is supported by a mainly qualitative reasoning module. AHMM4GBE's formalism mimics the human brain, by using empirical processes that are mainly based on heuristics. The AHMM4GBE is used to implement a decision-making system (or an expert system) to support a GBE and uses a behaviour-driven development environment that can be easily adopted by any organization. The development environment can be used by any team member without any prior computer sciences qualifications. The AHMM4GBE is used to estimate the Role of AI in GEB's (RAIGBE) context and tries to estimate the roles of the giants in this domain, like USA, China, and India; and what would be the real role of the European Union and France.

The uniqueness of this research is that the AHMM4GBE promotes a holistic unbundling process, the alignment of transformation strategies to support GBE's evolution. For a successful integration of the AHMM4GBE in projects, the manager's profile and role are crucial, where his decisions are supported by the selection, implementation and processing of critical success factors. A holistic systemic system approach is the optimal choice to integrate an RAI4GBE.
\end{abstract}

\section{Introduction}

Actual archaic Educational (or Business) Transformation Projects (simply a Project) are managed as silos where their components create a messy hairball that is called an Information and Communication System (ICS).

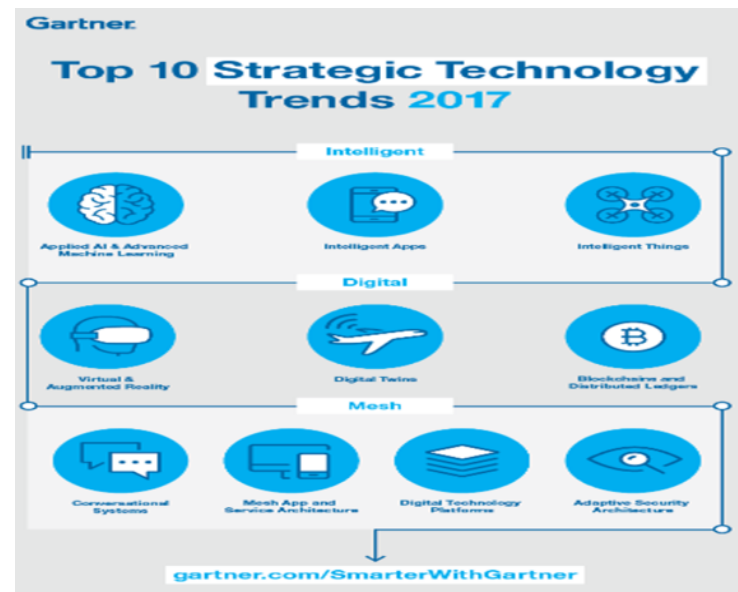

Figure 1. Technology Trends (Cearley, Walker \& Burke, 2016). 
To avoid such a failed scenario, this article recommends the usage of a central AHMM4GBE based Decision Making System for GBE (DMS4GBE) to solve business problems, by offering a set of possible solutions. Solutions have the form of recommendations for any type of GBE problem. Problem solving uses a central qualitative method that is based on a beam search (a heuristic tree's processing), where it uses quantitative methods at its nodes. DMS4GBE's actions produce solutions which can be applied by GBE specialists to support the implementation of a Project. A DMS4GBE is a multi-objective and multiCritical Success Factors (CSF) based system oriented for problems' solving and its main goal is to maximize the Project's success rate. As shown in Figure 1, the major strategic technology trend is AI which is RAI4GBE's main construct (Cearley, Walker \& Burke, 2016). The RAI4GBE supports a generic and cross-functional reasoning engine that is mainly based on: 1) CSFs' classification and management mechanism; 2) An adapted qualitative heuristics tree research method; and 3) a set of quantitative modules that can be triggered from its tree's nodes. AHMM4GBE's holistic concept is mainly business driven and is agnostic to a specific organization (Trad \& Kalpić, 2020a).

\section{Background}

The Project's technical implementation phase is the major cause of the high failure rates; therefore, the Manager's needs skills should encompass: 1) Enterprise Architectures (EA), business process management and services technologies; 2) unbundling environments; 3) agile project management; 4) AI, algorithmics and mathematical models; 5) organizational engineering; 6) global educational environments; 7) financial management; 8) the implementation phase's know-how; and 9) technology integration strategies. For these reasons, the author recommends a manager with an extended technocrat's profile (Farhoomand, 2004) that needs to be complemented with various cross-functional skills. More specifically, this research focuses on the influence of the Managers' AI, high-tech and EA experience, background and education. Projects integrate avant-garde knowledge and services technology components. To be successful, a GBE must incorporate AI based tech to outperform their adversaries. Actually, there are many methodologies that can be used to implement Projects (Gartner, 2016), but all of them lack a holistic and anti-lockedin approach. The Manager can integrate an DMS4GBE in EA's roadmap, in order to support the Project's complex and risky implementation phase (Zaiane \& Ben Moussa, 2018). The AHMM4GBE delivers a generic skeleton for the DMS4GBE that is capable to deliver just-in-time solutions. This article's research methodology is based on 1) A multi-domain literature review; 2) A mainly qualitative methodology; 3) A secondary quantitative methodology; and 4) An engineering-controlled experiment; which is the optimal methodology that can be applied in engineering projects (Easterbrook, Singer, Storey \& Damian, 2008). The RAI4GBE uses CSFs that are stored in Critical Success Areas (CSA) and are managed by the author's framework.

\section{The Author's Framework and Research Concept}

The research concept is a part of the Transformation, Research, Architecture, Development framework (TRADf), which is composed of various modules. In this article, parts of previous works are reused for the better understanding of this complex concept. If everything was referenced, it would have been very difficult to follow and understand this article (Trad \& Kalpić, 2011, 2016). This research concept can be considered as a non-conventional and pioneering one, in the field of Projects related to GBE systems. The used mixed method can be considered as a natural complement to conventional Quantitative Analysis for GBE (QNA4GBE) and Qualitative Analysis for GBE (QLA4GBE) methods. Both methods are compatible, and the difference is in the scope and depth of the research process. Empirical research validity checks if the research concept is acceptable as a contribution to existing scientific (and engineering) knowledge. In this article, the author tries to prove that the resultant recommendations and Proof of Concept (PoC), or experiment, are valid and applicable. Using Google's scholar online search portal, in which the author combined the previously mentioned keywords and other major key topics; the results show very clearly the uniqueness and the absolute lead of the author's works/framework in the fields of transformation methodologies, complex research projects and enterprise architecture. It can be considered as an important jumpstart for the future scientific and industrial use.

\section{The Research Question and Knowledge Gap}


In previous phases of research, the author concluded that a manager is an Architect of an Adaptive Business Information System (AofABIS), who has in-depth knowledge of business environments and the CSFs that are important. This defined the first step for the implementation of a successful Project, but the Manager must also have in-depth knowledge of: 1) Agile environments and EA; 2) AI and integrated development environments; 3) Businesspeoples' integration; 4) Project management; and 5) coordination of implementation engineers (Trad, \& Kalpić, 2014a, 2014b). This article's Research Question (RQ) is: "What is the role of AI in Global Business Education?". The targeted domain is the role of France and the European Union in this global competition.

\section{Artificial Intelligence}

The European Commission defines AI, as a system that shows intelligent behavior, by analyzing the targeted environment and that can perform various tasks with autonomy, in order to achieve defined goals (European Commission, 2019). AI has the following fields (McCarthy, 1989; Bohnhoff, 2019): 1) Mathematical models and algorithms; 2) Deicison trees; 3) Learning fields, like Action Research (AR); 4) Automated scheduling and planning; 5) Technology, resilience, and processing environments; 6) Robotism, automation, and recognition; 7) Data based decision approach; and other advanced topics. The author's mixed method is based on AR, which is an interactive inquiry process that balances problemsolving actions. AR actions are implemented in a collaborative context using a data-driven collaborative analysis. AR tries to understand underlying causes which enables future predictions about organizational changes, as an iterative learning process, where AI is a strategy (or concept) and not a product.

\section{Critical Success Areas, Factors}

CSA is a selected set of CSFs, where a CSF is a set of Key Performance Indicators (KPI). Each KPI corresponds to a Project requirement and a problem type. For a given requirement (or problem), an initial set of CSAs and their CSFs is defined and then managed by the DMS4GBE. CSFs are important for the mapping between problem types, knowledge constructs and organisational items. CSFs reflect possible problem types that must meet strategic Project goals and predefined constraints. Once the initial set of CSFs has been identified, then the Project can use the DMS4GBE to propose a set of solution types. Measurements are used to evaluate CSA's performances. The RAI4GBE delivers a set of solutions and recommendations (Trad \& Kalpić, 2020a).

\section{The AHMM4GBE}

The AHMM4GBE includes a dynamic defined nomenclature used to facilitate the integration in any Organization. AHMM4GBE's structure and is a set of coordinated modules, delivers solutions that correspond to various just in time processing schemes. The basic AHMM4GBE's nomenclature that the base for DMS4GBE, is presented in Figure 2.

Iteration
microRequirement
CSF
CSA
Requirement
microKnowledgeArtefact
neuron
microArtefact
microEntity or Enterprise
Entity or Enterprise
microArtefactScenario
Decision Making/Intelligence
EnityIntelligence
MM(Iteration) as an instance

Basic MM's Nomenclature
$=$ An integer variable that denotes a Project/ADM iteratio:
$=$ KPI
$=\Sigma \mathrm{KPI}$
$=\Sigma \mathrm{CSF}$
$=\underline{\mathrm{U}}$ microRequirement
$=\underline{\mathrm{U}}$ knowledgeItem(s)
$=\underline{\mathrm{action}}{ }^{\circ}$ data + microKnowledgeArtefact
$=\underline{\underline{U}}(\mathrm{e})$ neurons
$=\underline{\mathrm{U}}$ microArtefact
$=\underline{\mathrm{U}}$ microEntity
$=\underline{\mathrm{U}}$ microArtefactDecisionMaking
$=\underline{\mathrm{U}}$ microArtefactScenario
$=\underline{\underline{U}}$ Decision Making/InteligenceComponent
$=$ EnityIntelligence(Iteration)

Figure 2. AHMM4GBE's nomenclature (Trad \& Kalpić, 2020a).

AHMM4GBE's instances supports the DMS4GBE, by using CSFs weightings and ratings (in phase 1) and based on multicriteria evaluation (selected and defined constraints). 


\section{Organization/Enterprise Architecture as an Applied Mathematical Model}

A generic Organizational EA model and its Architecture Development Method for GBE (ADM4GBE) are the kernel elements of this research. Where ADM4GBE links DMS4GBE's (and its internal QLA4GBE) microartefacts to the Organization's structure. The AHMM4GBE and its underlining set of created instances is mainly a QLA4GBE beam-search heuristic tree (Della Croce, \& T'kindt, 2002). In each tree's node a precise call to DMS4GBE functions (or other) can be executed. GBE's transformation model uses an objective function, for the maximization or minimization.

\section{The Role of Enterprise Architecture}

\section{The Architecture Basics}

Project's EA, known also as the target architecture, in which Project teams align the traditional Organization's EA's vision. The traditional Organization's EA layers, represents a silo model where it is very hard to melt down into an agile EA. In fact, it represents a hairball of silo sub-components of domain and technology entities. Moving to a standardized EA is the first step to a just-enough architecture.

\section{Integration of the ADM4GBE}

ADM4GBE's integration in Projects, enables the automation and auto-generation of AI and other microartefacts, throughout all ADM4GBE's phases. The ADM4GBE encloses cyclic iterations, where information about all EA phases' activities is logged. ADM4GBE's is not dedicated to any specific Organization, domain or technology platform.

\section{Global Architecture Capability}

Understanding the Organizations and adapting the optimal EA, assumes that the Manager is capable of optimizing all of the Organization's heterogeneous and dislocated processes, into a holistic integrated GBE. A GBE is agile can be adapted to any Organization's EA strategy. Managers know that the effective management and integration of data-information through ICS' related technologies, is a key CSF to Project's success and an indispensable means to achieving GBE's sustainable competitive advantage.

\section{Project Risk Readiness Assessment}

Project Risk Readiness Assessment has the following characteristics (The Open Group, 2011a):

- The Manager must have in-depth knowledge of the EA's Business Transformation Readiness Assessment (BTRA); which means that he has the Capacity to Execute and the ability to perform all the ICS tasks required by the Project, including the skills, tools, processes, and management capability for the implementation phase.

- The Manager must also design the Enterprise Capacity to Execute; which is the ability of the Organization to perform all the tasks required by the endeavour, in areas outside of ICS, including the ability to make decisions, using the built-in tree reasoning model, within the time constraints; that is very typical to Projects based upon similar complexity of endeavour.

\section{Project Risk Activities}

Project Risk Activities have the following requirements and characteristics (The Open Group, 2011a):

- The Manager has to identify the Business Transformation Risks and Mitigation Activities.

- The proposed recommendations curriculum enforces the Managers' profile. Where, the Manager uses the ADM4GBE to manage the implementation phase.

- GBE Transformation Readiness.

EA has the ability to perform all Project tasks, including defining skills, tools, processes, and management capabilities. Enterprise Capacity is the ability of the Organization to perform all the tasks required by the endeavor, including the ability to make decisions within the tight time constraints. The Organization has a demonstrated ability to deal with GBE portfolio management and requirements. Transformation Readiness has the following characteristics (The Open Group, 2011a):

- The Manager who has a profile of an Architect of Adaptive GBE (AofAGBE), which is an extension of the previous AofABIS profile, must have in-depth knowledge of framework's BTRA; which means that he has the capacity to execute all the GBE tasks required by the Project, including the holistic management skills, modeling background, AI modules, GBE processes, and hands-on management capability for the implementation phase. 
- In the last years, there has been successful execution of similar complex projects, and there are appropriate standardized processes, methods, modeling skills, and a heuristics-based model for deciding what skills and activities are needed.

- The Manager must also design the Organization's capacity to function, which is the ability of the Organization to perform all GBE's tasks, in areas not related to ICS and AI technologies, including the DMS4GBE, using the tree reasoning model, within the limited time constraints.

- The Manager has to demonstrate the ability to manage such a DMS4GBE, related issues and GBE requirements and there a need for knowledge and needed skills.

\section{Business Integration and Inter-operability}

GBE's Integration and inter-operability have the following requirements and characteristics (TOGAF, Catalog, 2011):

- Integration supports the Organization's link with GBE's eco-system and in turn insures its sustainability.

- Inter-resources operability is supported by an interchangeable format, that makes the Organization's interfaces generic, standardized and independent.

- EA tools support the serialization of GBE processes that use serialized and standardized format file.

- This interchange format supports GBE's integration process, that facilitates the use of the interaction matrix, which shows the mapping between the services and functional domains.

\section{Business Infrastructure and Business Development Environments}

Managing GBE's infrastructure, by the Manager, implies that he must be capable of modeling the transformed agile platform that is based on: 1) Resources sharing; 2) High availability; 3) Load-balancing; and 4) Voluminous data storages. Organization's security is also important, where the Manager has to have the skills needed to define GBE standards on how to design and implement security concepts for processes, in a way to protect GBE's logic from being copied, so the Organization can avoid erosion. There are many modeling strategies to achieve that goal.

\section{Tools for Architecture and Modeling}

Managers who focus on delivering business outcomes must understand that the Project's EA tools, which comprise an important investment that can be wasted if not prepared correctly. Selecting and adapting any tool requires also understanding the vendor placement in the market. A tools roadmap is centralized and inter-operable across the entire GBE.

\section{Assess Readiness for Business Transformation}

A BTRA can be used to assess GBE's readiness to undergo a Project, where this assessment process is based on the analysis (and rating) of a defined set of readiness CSFs. The results of the readiness assessment are combined with a capability assessment process. These results are then used to shape the scope of the EA, in order to identify the activities required within the GBE and to also identify the eventual risk areas (The Open Group, 2011a).

\section{Identify the Transformation Risks and Mitigation Activities}

Used to identify the risks associated with the Architecture Vision concept and to assess the initial levels of risk (like, catastrophic, critical, marginal, or negligible) and the potential frequency associated with them. A mitigation strategy for each risk must be also assigned (The Open Group, 2011a).

\section{Confirm Readiness and Risk for a Project}

Used to review the findings of the BTRA that was previously conducted in Phase A and to determine their impact on the Architecture Roadmap and the Implementation and Migration Strategy. In this phase, it is important to identify, classify and mitigate risks associated with the Project. All risks are documented in the Consolidated Gaps, Solutions and Dependencies matrix. Project's implementation requires knowledge and awareness of GBE's transformation CSFs that impact the visionary state, in which evolution ICSs CSFs are crucial. GBE's Implementation and Migration Plan has to take both into consideration and neglecting them and focusing on the ICS will result in a fragile GBE (The Open Group, 2011a). 


\section{Lean and Automated Systems for an Agile GBE}

Project's success is also measured by intangible CSFs and benefits because they insure its long-term Organization's survival. These agile mechanist Organizations needs a generic approach based on Service Oriented Architecture (SOA), that has created a deep paradigmatic shift in GBE. It is replacing colossal monolithic traditional systems with its traditional applications, which split across GBE.

\section{AI based DMS4GBE}

AI systems management refers to expert systems and global systems modelling, which is supported by the EA's mapping concept. AI systems management is an approach for building and deploying intelligent systems and it replaces conventional GBEs with DMS4GBE (Daellenbach \& McNickle, 2005).

\section{GBE Services}

Cross-functional GBE's concept permits the linking of Organization's components using the ICS, automated domain processes and services. The unbundling of the monolithic GBE, is modelled by the Manager who must have extensive skills, he breaks down the actual monolithic GBE into a repository of services. This is basically an alignment of GBE's resources that is based on the 1:1 concept. GBEs must support a variety of different actors including browsers, browsers, and native applications. GBE handles service requests by executing processes (Richardson, 2014).

\section{Architecture and Modeling}

Architecture and modeling strategy for the selection, modeling strategy, education, and training framework, is to establish a modeling pattern that plugs-in a standardized EA and the unified modeling language methodology.

\section{Data Modeling Pattern}

The complex description of data models and related modelling patterns, does not do depend on the types of databases that are used; but the diversity of data-sources generates major problems in Projects, especially in its implementation phase.

\section{Knowledge Management Pattern}

The processes has to persist GBE knowledge and today there are the following artefacts: The processoriented knowledge management framework will be applied for the Project's knowledge management component that will help in the selection, modeling strategy establishment and training activities which will use just-in-time knowledge assistance. It will also help the Managers in updating and delivering the acquired knowledge on...

\section{Integrating a Continuum}

EA supports the Manager to manage Projects, by linking GBE and its ICS. CSFs and recommendations are the base of a tuneable RAI4GBE. GBE recommendations are needed for finding the optimal Managers' profiles needed to manage the design and implementation of Projects. There has been a lot developed and written on enabling success in Projects, but the author proposes to inspect why Managers fail in the implementation phase of Projects. That is mainly due to the Managers' lack of knowledge in managing integration and implementation of a continuum.

\section{Management of Resources, Artefacts and CSFs, Using AHMM4GBE}

TRADf's mapping strategy is used to relate and assemble the Project's microartefacts, requirements and resources. This mapping concept is used to automate the building and deployment of Project microartefacts' instances in all Project's phases; and is based on DMS4GBE that maps the Project's microartefacts to CSFs (The Open Group, 2011a). The Project's has to define the initial set of CSFs.

\section{The Role of Finance}

\section{AI based Financial and Technology Strategies}

AI has transformed Financial and Technology (Fintech)offering and improved capabilities that depends on the used platform. Banks have spent \$5.6 billion USD on AI and Machine Learning (ML) platforms in 2019, which is a fraction of profits that are estimated to $\$ 250$ billion USD. Where the main 
CSFs are, automation of tasks, to focus on strategic objectives, to support customers and to detecting fraud and financial crimes. Fintech's main activities areas are (Buttice, 2020):

- Fraud Detection and Compliance: according to Alan Turing's Institute, with $\$ 70$ billion USD spent by banks on compliance tasks in the U.S. The amount of money spent on fraud is staggering. AI is important in detecting financial fraud. ML is able to process massive data points in seconds and to identify erroneous transactions.

- Improving Customer Support: a critical application of AI in Fintech is customer service. Chatbots are a dominate capacity in all other verticals and are also gaining ground in the banking industry.

- Preventing Account Takeovers: an important part of our private identity has become public, and cybercriminals steal private data to access people's accounts and assets.

- Next-gen Due Diligence Process: mergers and acquisitions due diligence is an intensive process, requiring an important workload, a large set of paper documents and physical space to manage and store the data. Today the scope of due diligence is more ambitious, encompassing ICS, intellectual property, tax information, regulatory norms, and many other topics. AI and ML are transforming this field and adapt rapidly.

- Fighting Against Money Laundering: detecting money laundering and terrorist activities financing schemes are the most important challenges. AI, Artificial Neural Networks (ANN) and $\mathrm{ML}$ algorithms are more efficient than traditional statistic method in detecting financial crimes and organized predators.

- Data-Driven Client Acquisition: similar to any sector with different players offering services to a customer base and where competition exists. Efficient marketing is vital to acquire clients and AI/ML assists by applying behavioral and risk mitigation intelligence. AI based research and global information supports the understanding the drivers of churn and customer acquisition.

- Computer Vision and Bank Surveillance: in the U.S., Federal Reserve and banks are targeted by 3,000 robberies every year. Vision-based and recognition applications are used to support security systems.

- Easing the Account Reconciliation Process: account reconciliation is a sensitive point in the financial closing process. Organizations face account reconciliation challenges which is a tedious and a complex process that is managed by AI/ML processes.

- Automated Bookkeeping Systems: Organizations are often challenged by complex back-office's activities. AI based automated bookkeeping is able to assist Organizations in complex backoffice tasks, from accounting to managing payrolls. Applying ML with custom rules, processes, and calculations, supports the system to combine various data sources and to identify transaction patterns.

- Algorithmic Trading: the first Automated Trading Systems (ATS) was implemented in the 70's, algorithmic trading reached new heights dur to AI systems. It is not only about implementing rules to trade on the global markets, modern ATS can learn from data structures by using ML (and deep learning).

- Predictive Analytics and the Future of Forecasting: accurate cash forecasting is particularly important for treasury professionals to fund distribution accounts, make optimal decisions for borrowing (or investing), maintain target balances, and satisfy all regulatory requirements. Business professionals are unable to forecast by using many variables (or CSFs) required for the correlation and regression analysis processes. Predictive analytics uses ML, data mining and modeling to historical and real-time QLA4GBE to predict events and enhance cash forecast.

- Detecting Signs of Discrimination and Harassment: various types of dynamics exist in financial services, especially since it is an industry dominated by predators. Awareness has increased and many Organizations filed discrimination complaints and they were retaliated against, which means that the majority of victims are demoralized. 


\section{The Role of Accounting \\ Predator Tactics}

Concerning predator financial tactics, where the most damaging fact, is that the Project fails, what can negatively affect the Organization's sustainability and it can leave it to become prone to rigorous accounting austerity procedures. In this article, the author proposes a set of recommendations on how to avoid such blocking and damaging situations. Today many advanced RAIGBE related finance and accounting automation concepts exist. This article can support Projects through the automation of all its financial operations and their related accounting processes. That also enables the underlying RAIGBE to control accounting systems which interacts with global eco-systems. The RAIGBE can detect predator's resulting financial problems, crimes and irregularities.

\section{Automated Accounting}

RAIGBE promotes financial engineering that uses references to various types of asset management and related financial activities, like in the case of Project's accounting. These activities are conducted by different types of avant-garde governance, ICS and business service technologies. The current form of integration is based on block-chains' automation. The RAIGBE can be applied to many types of Project accounting engineering subfields. Organizations are encountering pressure to manage their assets proactively and holistically, in order to ensure their ethical integrity and to avoid predators' scenarios. A Project needs a just in time decision making, planning and optimization activities; and to achieve that goal, the designed Project's process manages the inventory of the Organization's assets.

\section{Financial Predator's Strategy \\ Basics}

The Financial Predator's Strategy (FPS) is based on the following facts and assumptions:

- Financial crime is in general considered as the financial aspects used in the support of religious terrorist acts. States applying state crime exists (Agger \& Jensen, 1996), so various types of means are used to support state crime (like Switzerland), like religion, ideology...

- The use of psychology to stop all possible legal initiatives and even make predator related banks make substantial gains.

- The Nobel prize winner, the British economist, Angus Deatoon, warns about the destructive FPS (Le Monde, 2019). Such profiles can be classified as predator profiles.

- Destroying, various banking and financial institutions worldwide, which might be a menace for the predator-oriented banks. Like in the case of Lebanon... (Trad, 2019).

- Although Fintech can be used to tackle financial Cybercriminal, it seems that the countries that support massive financial crimes are making the largest investment in these innovative technologies (Ravanetti, 2016).

- FPS Model

- This section analyzes FPS' model that has the following main characteristics:

- The Swiss Union des Banques Suisse (UBS), is not just a bank, it is the skeleton of the Swiss financial system and closely related to the Swiss government apparatus...

- The Swiss UBS, in which 32 trillion US dollars are hidden in only one remote island, so the question is, how much money this so-called bank illegally detains? ... (Stupples, Sazonov \& Woolley, 2019).

- The Swiss locked-in Swiss model combines: 1) the power and blockage of the Swiss law; 2) Too Big to Fail banks are untouchable; 3) Banking secrecy; 4) Ultraliberal economy; 5) Rejection of local and global standards; and 6) A specific political environment.

- The peak of such a predator's behavior is the Fraud scandal related to the UBS that was hit with a historic fine and this incredible Fraud crime, was openly supported and protected by the Swiss Federal Court that makes FPS a state model (Alderman, 2019; Tagliabuejune, 1986).

- Accountancy crimes, committed by FPS accountants are daily business (Cornevin, 2020). 
- There are many predators Fraud cases that damage practically all countries, like the USA, France, Germany, Greece, many African countries, Lebanon and many other... The hidden capital is reused as a credit to some of poor countries.

- Some credible sources like the Global Forum on Transparency and Exchange of Information for Tax Purposes peer review in 2011, has identified important deficiencies in the legal foundations for transparency and corruption, especially in relation with effective exchange of information (OECD 2011, 2014).

- In the USA, a federal judge accused the UBS of causing catastrophic investor losses in residential mortgage-backed securities sold before the 2008 financial crisis that caused more than $\$ 41$ billion of damage of subprime and other risky loans in 40 offerings (Stempel, 2019).

- The financial crisis of 2007 (that lasted to the year 2009) was marked by widespread fraud in the mortgage securitization industry (Fligstein \& Roehrkasse, 2019).

- Paula Ramada estimated the amount of lost money due to the benchmark of interest rates debacle is estimated at $\$ 300$ trillion in financial instruments, ranging from mortgages to student loans.

- The Role of Education and Ethics

- The Nobel prize winner, the British economist, Angus Deatoon, warns about the destructive predator's professional graduating business schools and to stop this type of brutalities. The leading school with such a perception is the Chicago school and the Swiss HEC (Le Monde, 2019). Such profiles can be classified as predator profiles which should be filtered from a GBE system.

\section{Locked-in Situations and Building a Vision}

RAIGBE must define basic rules and objectives, in order to avoid financial locked-in situations. Locked-in situations can be defined as follows, "a situation where an investor is unwilling or unable to exit a position because of the regulations, taxes or penalties associated with doing so. This may be an investment vehicle, such as a retirement plan, which cannot be accessed until a specified retirement date". Financial or technological (or even a combination) locked-in, is when building the financial and technological structure of a GBE system. The Project team and Manager must be cautious of eventual various devastating locked-in scenario(s). Even though some countries like Switzerland offer attractive financial and tax package(s), this country applies a coordinated legal and financial locked-in trap; it is a sealed system and represents an unwritten concept that can at any moment sweep out the financial resources from any business environment and even powerful countries like, the USA and France. Swiss banks and other Swiss financial institutions are under no supervision, whatsoever and they are free to operate using hit and run tactics. That indirectly makes this country, the financial industry's super protector that sets up fortifications against any possible legal intrusion; even when these institutions are executing massive irregular, criminal and illegal activities (International Monetary Fund, 2009). Fintech based locked-in, implies that technologies in the actual financial domain, influences its productivity, growth and monetary policy. It supports also sophisticated predator crime schemes. It is a technology-driven domain and because of its hyper evolution depends on technology, the financial institution can be driven easily in a locked-in situation (Balling, Lierman \& Mullineux, 2003). RAIGBE should avoid adopting a unique tool, the so-called all-in-one Fintech tools.

\section{Slavery and Financial Aggressiveness}

Looking at the cultural background, the legendary Germanic (mainly Germans, Swiss and Austrians) hatred of Semites and their support of the great Ottoman genocides, added to the fact, that major Nazi officers became consultants of pan-Arab genocidal dictators and executive bankers of major Swiss banks. There is also the case of slavery, discrimination and racism in Germanic central Europe and more specifically in the regions of the peace-loving Helvetic Confederation, where Swiss historians, who are supported by dozens of major public figures, launched a committee that inspects the case for organized and structured worldwide slavery. This massive case of slavery was directed and managed by Swiss bankers and political leaders. This committee's main aim is to estimate reparations in the context of Switzerland's related organize slavery crimes against humanities. In these crimes' major Swiss high-level politicians, 
trading companies, world class banks, cantons (like the Canton of Vaud, who still carries a slavery apartheidic mentality), predatory family enterprises, mercenary contractors, soldiers and private individuals. All mentioned Swiss organizations profited from organized slave trade. Switzerland organized financial links to the slave trade and can considered global predators of manhood and nationhood. These facts show this nation's culture of financial greediness that comes out always, exactly like in the period of the second world war and the case of plundering of victims of the Holocaust (Swissinfo, 2019).

\section{Legal and Regulatory Constraints to be Integrated}

To design and implement an adequate regulatory component, there is a need to implement an AHMM4GBE based legal intelligence module (Gray, 1997). The International Organization of Securities Commissions (IOSCO) identified eight areas that actually constitute what is currently called Fintech. Such areas are payments, insurance, planning, trading and investments, blockchain, lending/crowdfunding, data and analytics and security. The growth of the Fintech market implies a number of relevant issues and risks from a legal and governance perspectives. In this respect, financial regulation is increasingly complex with major financial entities required to comply with strict regulations in various jurisdictions. Like in various sectors, the complexity for regulators is to find the right balance between Fintech, national cultures and the need to regulate them correctly. Based on the European Banking Authority's report on prudential risks and opportunities, there are legal issues that have to be considered when dealing with Fintech.

\section{The Role of Global Education and Profile Definition}

RAI4GBE supports GBEs and the profile's selection, which will hopefully help to minimize Project's failure rates. Profiles depends on the type of activity. The RAI4GBE can be used in various GBE's subdomains, and it helps in the selection of the future Managers, who are capable of designing the change processes. Such Managers are also specialized in designing solutions endemic to Projects (Doyle, 1995).

\section{The Anglo-Saxon Model}

The college degree choices of Jeff Bezos and other CEOs like, Bill Gates and Mark Zuckerberg who dropped out of college, but they became wealthy entrepreneurs. In this model, a degree is not a step to success. Ultimately, if getting mega-rich from business is a goal, there is no prescribed path. Success has to do with meeting the right opportunities and a specific way lessons are interpreted. Mark Zuckerberg, Bill Gates, and many others, did not even complete their degrees (Schwantes, 2020). These facts are pushing the notions of certifications that are considered more valuable than university degrees.

\section{The European Model}

Mainly the European continental part can be presented with the case of Serge Dassault, a French engineer, businessman and politician. He was the chairman and chief executive officer of Dassault Group. He graduated the prestigious École Polytechnique, SUPAERO and HEC Paris. This is the case of many European Managers and will this tendency continue is an uncertainty.

\section{Instructional versus Academic Organizations}

The main differences between these two disciplines are (Rob \& Roy, 2013):

- Certifications attract hiring Managers, who suggest the implementation of certifications in traditional university programs.

- Certifications have been integrated in university programs and there were difficulties because certifications are based on commercial tools. This is a very commercial approach.

- The frequent changing nature of certifications is every two years.

- Certification programs can improve traditional lecturing and converge with standards.

- Students are interested in certifications.

- This can on the long-term, lock in many countries and Organizations, as AI tools come from a single mainstream.

- Certifications are superficial and can just assist a specialist, but an academic diploma stays essential.

\section{Ethical Principles}


The author based his approach and framework on the following main ethical principles (Murray, 1996):

- Content competence: a university professor or teacher maintains a high level of matter knowledge and ensures that his courses' contents are ethical, current, accurate, representative, and appropriate to the program of studies and global ethical standards.

- Pedagogical competence: a pedagogically competent professor communicates the main courses' objectives to the students. And he is aware of possible instructional methods or strategies and adapts methods of teaching to research realities (including personal or selfreflective research). These methods should be effective in helping students to accomplish the objectives.

- Dealing with sensitive topics: students would find sensitive or discomforting topics embarrassing and that is why such topics should be presented in an open honest and didactical manner.

- Student development process: the teacher's responsibility is to contribute to the intellectual development of the student (in the teacher's area of expertise), and he should try to avoid actions such as exploitation and discrimination that detract from student development.

- Dual relationships with students: to avoid conflict of interest, a teacher does not enter into dual-role relationships with students. Such relationships may detract from students' development or may drive to favoritism on the part of the teacher.

- Confidentiality: student behavior, grades, attendance records and private communications are dealt with as confidential resources and are released only with student consent, or for legitimate academic purposes, or if there are reasonable grounds for believing that released communications will be beneficial to the student and the educational environment.

- Respect for colleagues: a university teacher respects his colleagues and works cooperatively with colleagues in the interest of academic development.

- Valid assessment of students: the importance of assessment of student performances in higher education is the teachers' responsibility. Where he makes the right steps to ensure that assessments are valid, fair, and congruent with course objectives.

- Respect for institution: in the interests of student development, a university teacher is aware of and respects the academic objectives, rules, and standards.

The author would add the following:

- In order to avoid the production of future predators, whose only goal is to gain a lot of money educational Organizations must include objectives other than just making money (Le Monde, 2019).

- To privilege ethics and to present cases of fraud and financial criminality like the case of the UBS and Switzerland, which are anti-academic (Stupples, Sazonov \& Woolley, 2019).

- To promote Nelson Mandela's moto, which is, education is the most powerful weapon which you can use to change the world...

- Jules Ferry, the legendary French minister of education, privileged the approach in making men equal in their rights, dignity, mutual respect in order to replace animosity. He used the moto, with unequal education, I challenge you to never have equal rights, not theoretical equality, but real equality and equal rights is the very foundation of democracy...

\section{Manager as a Cross-Functional Architect \\ Enterprise Architecture}

Understanding Organizations and the CSFs that can influence their survival and competitiveness, is only the first step towards a successful Project. The Manager must have in depth knowledge of: Project architecture and its development management, businesspeople integration, agile project management and management of computer engineers. The Manager acts as solution designer and implementation architect. Accordingly, this research unifies resources from distinct but related areas: business processes, ICS infrastructure and Project resources. EA develops concepts for the Manager's selection and proposes a 
method to weight and inter-relate his various skills with CSFs. Estimating Manager skills requires a profound knowledge of the Organization's architecture, business processes, services, ICS and Project management issues. That rounds up the profile of an AofABIS. The Manager is in fact a AofABIS, where he acts as a coordinator of architectures teams, business specialists and their various activities (Trad, \& Kalpić, 2013a, 2013b, 2013c).

\section{Enterprise Architecture Skills}

Another perspective of skills are the Project's architecture modeling skills that typically comprises: 1) Detailed business modeling; 2) Business building component design; 3) Business applications and actor's role design; 4) Requirement engineering; and 4) Standardized business integration, etc....

EA is considered as a superset of Business, Data, Application, and Technology Architecture is the Manager's main skill. A typical EA team undertaking the development of a Project architecture as described in TOGAF would comprise the following roles: 1) Architecture Board Members; 2) Architecture Sponsor; and 3) Architecture Manager.

\section{Categories of Skills}

An EA team skill set will need to include the following main categories of skills:

- Generic skills: comprises, leadership, teamworking, inter-personal skills, etc.

- Business skills and methods comprises, business cases, business process, strategic planning, etc.

- EA skills: comprises, modeling, building block design, applications and role design, systems integration, etc.

- Project management skills comprises, managing business change, project management methods and tools, etc.

- ICS general skills comprises, brokering applications, asset management, migration planning, SLAs, etc.

- Technical ICS skills: comprises, software engineering, security, data interchange, data management, etc.

- Legal skills: comprises, data protection laws, contract law, procurement law, fraud, etc.

\section{Modeling Skills}

Modeling strategy establishment skills comprise: 1) Business use cases design; 2) Business process modeling; 3) Business integration; 4) Strategic planning; and 5) services modeling, etc... The Manager must understand the business requirements, then he has to probe for business information, influence Project's team members, facilitate consensus in the implementation phase, synthesizes and translates strategic requirements into actionable tasks, manage CSF based risks, etc. The Manager participates in the discovery, modeling and design of the business scenarios that are the initial driving phase for the solution. The Manager manages the requirements and develops business models of components for the final agile business environment. Then he has to tune these business models through iterations to fit all business scenarios.

\section{Managerial Educational Benefits and Recommendations}

This research offers a set of GBE recommendations and benefits. TRADf's qualitative reasoning process model uses the recommendations to give the Project to tune the details of the Manager's profile (Vella, Corne, Murphy, 2009).

\begin{tabular}{|c|c|c|}
\hline By Importance & The Manager is an AofAGBE & \\
\hline 1 & $\begin{array}{c}\text { The Manager must have extensive experience in } \\
\text { Projects }\end{array}$ & \\
\hline 2 & The Project must avoid a locked-in situation & \\
\hline 3 & Implement a light version of ADM4GBE & \\
\hline 4 & An AI concept is a strategy and not a tool & \\
\hline 5 & &
\end{tabular}




\begin{tabular}{|c|c|c|}
\hline 6 & $\begin{array}{c}\text { Education and training, are academic and not a } \\
\text { certification farm }\end{array}$ & $\begin{array}{c}\text { Many AI domains and are redundant a GBE must } \\
\text { define its own AI strategy }\end{array}$ \\
\hline 7 & RAIGBE can be applied to any organization & \\
\hline 8 & Table $1 \quad$ The list of recommendation
\end{tabular}

\section{The Profile, Curriculum and Pattern}

GBE's curriculum must comprise the knowledge of business modelling and EA, automated real-time process environments, agile project management, organizational behavior, AI, and ICS implementation know-how (Trad, \& Kalpić, 2014a, 2014b). The profile and educational curriculum round up the GBE Manager's pattern.

\section{The Proof of Concept}

The PoC is implemented using TRAD $f$ which uses micro artefacts based on the "1:1" mapping concept.

\section{The Literature Review's Outcome}

The quantitative part of the mixed method that is made up of the set of CSFs. The surveyed types of specialists and managers were: 1) business and ICS school professors and directors, 2) managers of information systems, 3) project managers, 4) human resources, 5) educational professionals and transformation managers. The surveys confirmed the research RQ. The research shows that the Manager is an AofABIS. Therefore, a concrete TRAD $f$ was built and the PoC delivered the recommendations on how to select and train a Manager (Trad, \& Kalpić, 2014a, 2014b; SAP, 2012a). The literature review process' (or Phase 1) uses the research's archive of references and links that are analysed using a specific interface. After selecting the CSA/CSFs and linking them to micro artefacts scenarios; this concludes Phase 1. The PoC (or Phase 2), that uses a grounded hyper-heuristic to process solutions to a given problem.

\section{From Phase 1 to Phase 2}

AHMM4GBE's main constraints and the Project's components supports the PoC. A main constraint is that a CSA average must be higher than 7.5. In this PoC's CSA/CSFs evaluation, has an average result higher than 8 , as shown in Table 2.

\begin{tabular}{|c|c|c|c|}
\hline Critical Success Factors & KPIs & & Weightings \\
\hline CSF_RAIGBE_Framework_ResearchProject & Proven & - & From 1 to 10.10 Selected \\
\hline CSF_RAIGBE_EA & Proven & $\bar{F}$ & From 1 to 10.10 Selected \\
\hline CSF_RAIGBE_DMS4GBE & Feasible & - & From 1 to 10.09 Selected \\
\hline CSF_RAIGBE_Finance & Complex & - & From 1 to 10.08 Selected \\
\hline CSF_RAIGBE_Education_Ethics & Complex & + & From 1 to 10.08 Selected \\
\hline CSF_RAIGBE_Profile_Definition & VeryComplex & - & From 1 to 10.07 Selected \\
\hline
\end{tabular}

Evaluate

Phase 2, the Setup

Table 2. The outcome of Phase 1 has an average of 8.60 .

The PoC uses TRADf's development environment to configure the DMS4GBE and selects problems, actions and applicable solutions to verify RAIGBE's feasibility. The case study is a concrete insurance case.

\section{Linking the Applied Case Study - Integration and Unification}

The PoC and the ArchiSurance case with goals as shown in Figure 3, it analyses a merger, of an old system's landscape that has become siloed, that results in abundant data and code. The PoC, a financial auditing scenario. 


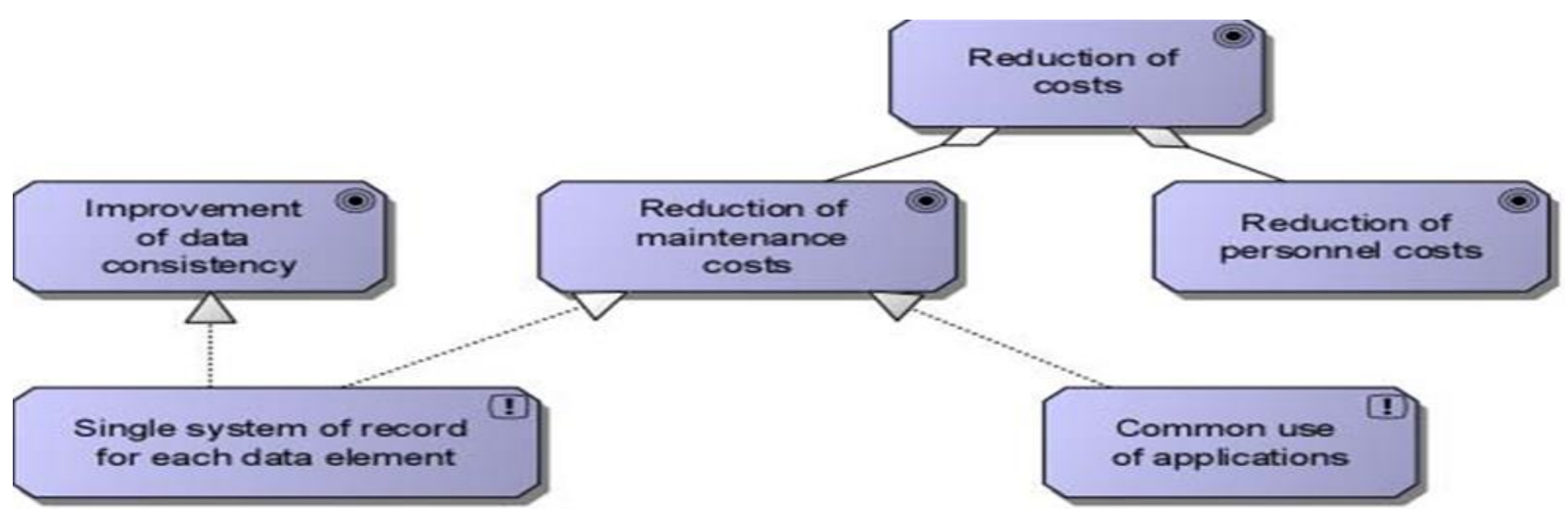

Figure 3. Transformation goals (Jonkers, Band \& Quartel, 2012).

\section{PoC's Processing on a Concrete Tree Node}

In Phase 2, the hyper-heuristics approach is used, to find a combination of heuristics' action, used to solve a problem related to the RQ. A selected CSF is linked to a problem type and a related set of actions where the processing starts in the root node. Each problem, like this case the PRB_GBE_Single Data Record System problem, has the following set of actions:

ACT_GBE_Single Data Record System Define Possible Audit Processing

For this DMS4GBE related PoC, the author has selected the CSF_GBE_Single Data Record System_ Validation as the active CSF, taken from the CSFs pool. In this PoC the goal is to find solutions related to this selected CSF's related problems. The author has decided to apply the AHMM4GBE based reasoning to try to solve the CSF_GBE_Single Data Record System Validation issues and the related problem or the PRB_GBE_Single Data Record System_Validation, which is solved by using the following steps:

- Relating the case infrastructure and financial transactions' integration capabilities to CSF_GBE_Single Data Record System_Validation capabilities is done in Phase 1.

- Link the processing of this node to the pseudo-quantitative modules, then by using qualitative modules, filter and deliver the initial state that is the root node of the decision tree.

- The internal heuristics engine is configured, weighted and tuned using configuration information.

- The set of possible solutions results from the hyper-heuristics decision model. Then the reasoning engine is launched to find the set of possible solutions in the form of possible improvements.

- From the Tardif client's interface, the development setup and editing interface can be launched to develop the finance related data services to be used in micro artefacts.

\section{Selected Node Solution in Phase 2}

The development scripts make up the processing logic of the RAIGBE's defined problems and is supported by a set of actions. Where these actions are processed in the TRADf background to support service micro artefacts that are called by the engine's actions, which deliver the solution and the flow of steps

\section{Conclusion}

The empirical phase of this research tries to prove the RQ and delivers an optimal GBE profile definition of the Manager and a set of recommendations. GEB's characteristics are needed to holistically manage the design and to implement an educational environment. More specifically, the author gives an overview of the research in grounded hyper-heuristics model internals, used by the DMS4GBE. The research's most important findings are:

- A concrete framework: TRADf is a concrete framework used to implement an RAI4GBE.

- Knowledge gap: The literature review found a gap between the traditional approaches and needed GBE. 
- Evolutionary mixed method: This research uses a AHMM4GBE in order to create: 1) the role of AI for GBE; 2) the Manager profile; and 3) GBE prerequisites.

- The PoC: delivered the research's recommendations on how to implement an RAI4GBE.

- Manager Profile and educational prerequisites: Organizations produce general profiles that can hardly cope with heterogeneous complexity and fast changes. These high frequency changes are mainly due to the hyper-evolution of $\mathrm{AI}$ and technology. The research confirms the role of Manager as a AofAGBE.

- Estimating of the Manager skills: requires a profound knowledge of EA, SOA, AI and agile project management; this rounds up the profile of an AofAGBE.

- Europe's and France's approaches: are doing very well in the related academic fields, but concerning the industrial part, it is practically inexistant. It finds itself in a locked-in situation and it has to establish a strategy to join the major GBE and AI players.

\section{References}

Agger, I., \& Jensen, S. (1996). Trauma and Healing Under State Terrorism. London: ZEB Books.

AMInfo. (2014). Middle Eastern clients in the HSBC Switzerland leaks. Swiss Leaks. Retrieved from http://ameinfo.com/luxury-lifestyle/list-middle-eastern-clients-in-the-hsbc-switzerland-leaks

Balling, M., Lierman, F., \& Mullineux, A. (2003). Technology and Finance: Challenges for Financial Markets, Business Strategies and Policy Makers. NY: Routledge.

Buttice, C. (2020). Top 12 AI Use Cases: Artificial Intelligence in Fintech. AltaML-Techopedia. https://images.techopedia.com/top-12-ai-use-cases-artificial-intelligence-in-fintech/2/34048

Cearley, D., Walker, M., Burke, B. (2016). Top 10 Strategic Technology Trends for 2017.

Cornevin, Ch. (2020). La police démantèle un vaste système de blanchiment de fraude fiscale... [Police dismantle massive tax fraud laundering scheme]. Le Figaro. France. Retrieved from https://www.lefigaro.fr/actualitefrance/la-police-demantele-un-vaste-systeme-de-blanchiment-de-fraude-fiscale-20200110

Daellenbach, H., McNickle, D. and DYE, Sh, (2012). Management Science. Decision-making through systems thinking. 2nd edition. Plagrave Macmillian. USA.

D'Amato, G. (1995). Switzerland: A Multicultural Country without Multicultural Policies? In Vertovec, S. \& Wessendorf, S. (Eds.) The Multiculturalism Backlash: European Discourses, Policies and Practices. NY: Routledge.

Della Croce, F., \& T'kindt, V. (2002). A Recovering Beam Search algorithm for the one-machine dynamic total completion time scheduling problem, Journal of the Operational Research Society, 53:11, 1275-1280. Taylor \& Francis.

Doyle, M. (1995). Organizational transformation and renewal: a case for reframing management development. Leicester Business School, De Montfort University, Leicester. UK.

Easterbrook, S., Singer, J., Storey, M., \& Damian, D. (2008). Guide to Advanced Empirical Software EngineeringSelecting Empirical Methods for Software Engineering Research. F. Shull et al. (eds.). Springer.

European Commission (2019). Digital Single Market. FACTSHEET / INFOGRAPHIC4 July 2019. European Commission.https://ec.europa.eu/digital-single-market/en/news/factsheet-artificial-intelligence-europe

Farhoomand, A. (2004). Managing (e)business transformation. Palgrave. UK.

Fligstein, N., \& Roehrkasse, A. F. (2016). The causes of fraud in the financial crisis of 2007 to 2009: Evidence from the mortgage-backed securities industry. American Sociological Review, 81(4), 617-643.

Gartner (2016). Gartner's 2016 Hype Cycle for ICT in India Reveals the Technologies that are Most Relevant to Digital Business in India Analysts to Explore Key Technologies and Trends at Gartner Symposium/ITxpo 2016, 15-18 November, in Goa, India. Retrieved April 3, 2018, from https://www.gartner.com/newsroom/id/3503417

Gray, P. (1997). Artificial legal intelligence. London: Dartmouth Publishing Co.

International Monetary Fund (2009). Switzerland: Financial Sector Assessment Program - Detailed Assessment of Observance of Financial Sector Standards and Codes. NY: International Monetary Fund.

Jonkers, H., Band, I., \& Quartel, D. (2012a). ArchiSurance Case Study. The Open Group.

Le Monde (2019). Le Prix Nobel d'économie Angus Deaton : Quand l'Etat produit une élite prédatrice [Nobel Lauréate in Economics Angus Deaton: "When the state produces a predatory elite]. Le Monde. Retrieved from https://www.lemonde.fr/idees/article/2019/12/27/angus-deaton-quand-1-etat-produit-une-elitepredatrice_6024205_3232.html

McCarthy, J. (1989). What is AI? Stanford University. USA. http://jmc.stanford.edu/artificial-intelligence/what-isai/index.html

Murray (1996). 9 Ethical Principles. Queens Univeristy. Canada.

https://www.queensu.ca/teachingandlearning/modules/ethics/04_s2_01_nine_ethical_principles.html 
OECD (2011). Global Forum on Transparency and Exchange of Information for Tax Purposes Peer Review: Switzerland 2011, Phase 1. OECD Publishing, Paris.

OECD (2018). Country Case Study 1: Lebanon. MENA-OECD ECONOMIC RESILIENCE TASK FORCE RESILIENCE IN FRAGILE SITUATIONS. 4-5 December 2018. Islamic Development Bank. Jeddah, Kingdom of Saudi Arabia. OECD.

Ravanetti, A. (2016). Switzerland Bank on Fintech with Lighter Regulations. Crowd Valey. Retrieved September 2019, from https:/ / news.crowdvalley.com/news/switzerland-bank-on-fintech-with-lighter-regulations

Rob, M., \& Roy, A. (2013). THE VALUE OF IT CERTIFICATION: PERSPECTIVES FROM STUDENTS AND IT PERSONNEL. Issues in Information Systems. Volume 14, Issue 1, pp.153-161, 2013.

https://iacis.org/iis/2013/192_iis_2013_153-161.pdf

Richardson Ch. (2014). "Pattern: Microservices architecture", available online at:

http://microservices.io/patterns/microservices.html

SAP (2012a). Business Process Management Business Transformation Academy. Germany.

Schwantes, M. (2020). Research Uncovers the Value of the College Degree Choices of Jeff Bezos and Other ObscenelyRich CEOs... INC. https://www.inc.com/marcel-schwantes/research-uncovers-college-degree-choices-of-jeffbezos-other-obscenely-rich-ceos.html

Stempel, J. (2019). UBS must defend against U.S. lawsuit over 'catastrophic' mortgage losses. Yahoo Finance. Yahoo. USA. Retrieved September 2019, from https://finance.yahoo.com/news/ubs-must-defend-against-u214743943.html

Stupples, B., Sazonov, A., \& Woolley, S. (2019, July 26). UBS Whistle-Blower Hunts Trillions Hidden in Treasure Isles. Bloomberg. Retrieved from https://www.bloomberg.com/news/articles/2019-07-26/ubs-whistle-blower-huntstrillions-hidden-in-treasure-islands

Swissinfo (2019). Swiss launch committee on slavery reparations. Swissinfo. https://www.swissinfo.ch/eng/history_swiss-launch-committee-on-slavery-reparations-/45421506

The Open Group, 2011a. The TOGAF. The Open Group.

TOGAF Catalogs (2011). "Sample catalogs, matrices and diagrams”, available online at:

http://www.opengroup.org/bookstore/catalog/i093.htm

Trad, A., \& Kalpić, D. (2011). The Selection, Training, Follow and Evaluation STF for Managers in Business Innovation Transformation Projects-A Holistic Overview. IEEE, Conference on Information Technology Interfaces. Croatia.

Trad, A., \& Kalpić, D. (2013a). The Selection, and Training framework (STF) for Managers in Business Innovation Transformation Projects - Overview of the development of the empirical model. IEEE 2013, BAME. Venice, Italy.

Trad, A., \& Kalpić, D. (2013b). 3rd position Award. The Selection and Training Framework (STF) for Managers in Business Innovation and Transformation Projects - The Design and Implementation of the Research Model, IMRA, Croatia.

Trad, A., \& Kalpić, D. (2013c). The Selection, and Training framework (STF) for Managers in Business Innovation Transformation Projects - The Literature Review. IEEE 2013, Centeris. Portugal.

Trad, A., \& Kalpić, D. (2014a). The Selection and Training Framework (STF) for Managers in Business Innovation and Transformation Projects - The profile of an Architect of adaptive business systems. IMRA, USA.

Trad, A., \& Kalpić, D. (2014b) The Selection, and Training Framework selection and training framework (STF) for Manager's in Business Innovation Transformation Projects - Educational Recommendations. EDEN; Zagreb. Croatia.

Trad, A., \& Kalpić, D. (2016). The Business Transformation Framework for Managers in Business Innovation Transformation Projects-A heuristics decision module's design concept. ABRMR.

Trad, A., \& Kalpić, D. (2020a). Using Applied Mathematical Models for Business Transformation. IGI Complete Author Book. IGI Global. USA.

Trading Economics (2017a). Switzerland - GDP Annual Growth Rate. Trading Economics. Retrieved from http://www.tradingeconomics.com/

VELLA, A., CORNE, D. and MURPHY, C. (2009), Hyper-heuristic decision tree induction. Sch. of MACS, Heriot-Watt Univ., Edinburgh, UK.

Zaiane, S. \& Ben Moussa, F. (2018). Cognitive Biases, Risk Perception, and Individual's Decision to Start a New Venture. International Journal of Service Science, Management, Engineering, and Technology (IJSSMET). IGI Global. DOI: 10.4018/IJSSMET.2018070102 